\title{
ARTICLE OPEN \\ Asthma control and management in 8,000 European patients: the REcognise Asthma and LInk to Symptoms and Experience (REALISE) survey
}

\author{
David Price ${ }^{1}$, Monica Fletcher ${ }^{2}$ and Thys van der Molen ${ }^{3}$
}

BACKGROUND: Asthma is one of the most common chronic diseases in the world, and previous studies have reported low levels of control. Recent developments in the availability and use of online sources of information about asthma might add to patients' knowledge and help improve control.

AIMS: To investigate whether asthma control has improved by assessing levels of symptoms, exacerbations and Global Initiative for Asthma-defined control in a real-life population of patients who use the Internet and social media, as well as evaluate patient perception of control and attitudes to asthma.

METHODS: Online surveys were conducted among 8,000 patients with asthma (aged 18-50 years, $\geqslant 2$ prescriptions in the previous 2 years, use of social media) from 11 European countries.

RESULTS: Levels of asthma control were low: $45 \%$ of respondents had uncontrolled asthma. Acute exacerbations were common: $44 \%$ of respondents reported having used oral steroids for asthma in the previous 12 months, $24 \%$ had visited an emergency department and $12 \%$ had been hospitalised. More than $80 \%$ of respondents (overall, and among those with a history of exacerbations) considered their asthma to be controlled. Of those who had an exacerbation requiring oral steroids, $75 \%$ regarded their asthma as not serious. CONCLUSIONS: Asthma control in Europe remains poor; symptoms and exacerbations are common. Many patients regard their asthma as controlled and not serious despite experiencing symptoms and exacerbations. There is a need to assess patients' control, risk and inhaler technique, and to ensure that patients are prescribed, and take, appropriate treatments.

npj Primary Care Respiratory Medicine (2014) 24, Article number: 14009; doi:10.1038/npjpcrm.2014.9; published online 12 June 2014

\section{INTRODUCTION}

Asthma is one of the most common chronic conditions in the world; according to the Global Burden of Disease Study, asthma caused more than 345,000 deaths worldwide in 2010.1,2 In Europe alone, asthma affects 30 million people, ${ }^{2,3}$ and the cost of asthma care in Europe is estimated at $£ 18$ billion per year; lost productivity accounts for almost $£ 10$ billion of this. ${ }^{3,4}$

Asthma control in clinical practice is suboptimal despite available therapies; ${ }^{5-7}$ over the last decade, European studies have shown little apparent improvement in the levels of symptom control. ${ }^{5,7}$ Poor asthma control is associated with increased risk of exacerbations, debilitation, impaired quality of life, increased health-care utilisation and reduced productivity. ${ }^{5,7,8}$ Asthma can remain uncontrolled in patients prescribed regular therapy, who may continue to experience exacerbations. ${ }^{7}$ Importantly, a history of asthma exacerbations is a risk factor for future exacerbations; hence, understanding predictive factors is important. ${ }^{9}$ Other risk factors include poor asthma control and poor adherence. ${ }^{9,10}$

International guidelines, such as those produced by the Global Initiative for Asthma (GINA), state that treatment should be based on a patient's level of asthma control defined by daytime symptoms, normal activities affected by symptoms, night-time awakenings and reliever inhaler use. ${ }^{2}$ The incidence of asthma control in clinical practice is considerably lower than the levels (up to 70\%) reported in many randomised controlled trials. ${ }^{11-13}$ This may be because randomised controlled trials are not representative of real life, because only a very small subset of patients from clinical practice $(1-2 \%)$ is eligible for inclusion, ${ }^{14}$ or because trial participation influences participants' behaviour (the 'Hawthorne effect'). ${ }^{15}$

Many patients may overestimate their symptom control and underestimate the severity of their condition, indicating that they tolerate symptoms and lifestyle limitations. ${ }^{7,16}$ Patients may describe symptoms more positively to their health-care professionals (HCPs) than they would when completing a validated questionnaire. To develop effective asthma therapies and to improve real-life outcomes, it is therefore important to understand, and adapt to, different patients' attitudes towards their condition and to tailor treatments to their specific needs. ${ }^{2}$ This requires effective communication, a valid assessment of control, a clear understanding between patients and HCPs, and greater patient knowledge about their condition.

Here, we report data from the REcognise Asthma and LInk to Symptoms and Experience (REALISE) survey, conducted in 11 European countries among 8,000 individuals who use social media - the largest and most recent survey of its kind. ${ }^{5,16-20}$ This survey assessed symptoms and levels of asthma control in a reallife setting and evaluated how symptoms and indicators of acute exacerbations relate to guideline-defined control and different treatment levels; in addition, current asthma control was analysed in relation to exacerbation history. Patients' perceptions of asthma control and symptoms were also explored. The data provide

${ }^{1}$ Centre of Academic Primary Care, University of Aberdeen, Aberdeen, UK; ${ }^{2}$ Education for Health, Warwick, UK and ${ }^{3}$ Department of General Practice, University of Groningen, University Medical Centre Groningen, Groningen, The Netherlands.

Correspondence: D Price (david@rirl.org)

Received 18 October 2013; revised 30 January 2014; accepted 6 March 2014 
important new insights into patients' attitudes and whether reallife asthma control has improved in recent years.

\section{MATERIALS AND METHODS}

Survey design

This quantitative, questionnaire-based survey was designed to:

- assess symptoms, indicators of acute exacerbations and levels of guideline-defined control in a real-life population of patients who use social media;

- compare asthma symptoms, exacerbations and control levels across different treatment levels (reliever inhaler only, single-drug preventer inhaler, combination preventer inhaler and combination preventer inhaler plus oral pill);

- report the incidence of past exacerbations stratified by current asthma control level;

- investigate respondents' perceptions of asthma control in relation to their guideline-defined level of control and history of exacerbations; and

- explore attitudes of patients towards asthma and its management, and investigate the sources of information preferred by patients who use social media.

The survey was conducted online in 11 European countries (Austria, Belgium, Finland, France, Germany, Italy, the Netherlands, Norway, Spain, Sweden and the United Kingdom), between July and October 2012, by Incite Marketing Planning Limited (London, UK), in accordance with the Codes of Conduct of the Market Research Society, European Pharmaceutical Marketing Research Association and Association of the British Pharmaceutical Industry, and guidelines from the British Healthcare Business Intelligence Association. Data were managed in accordance with the Data Protection Act (UK, 1998). The survey was supported by Mundipharma International Limited (Cambridge, UK).

\section{Questionnaire development}

The questionnaire was developed through a series of meetings with experts in the field and the authors, who provided input and advice on the questions, methodology and structure of the survey. A cognitive testing phase was conducted in Germany with six participants to ensure that questions were unambiguous and to test the validity and consistency of responses; minor amendments were made to clarify the questions. Questionnaires took approximately $30 \mathrm{~min}$ to complete.

\section{Survey population}

This survey was conducted among individuals aged 18-50 years who confirmed that they had been diagnosed with asthma by a doctor, had at least two prescriptions for asthma in the previous 2 years and used social media. Respondents who had participated in market research surveys within the previous 3 months were excluded.

The survey population was drawn from validated consumer panels, which were mainly recruited online (Watermelon Research, London, UK). In Norway and Finland, recruitment was supplemented by press advertising. Approximately 590,740 members of the general public (regardless of asthma status) who had previously registered on consumer panels and had agreed to take part in market research were sent an e-mail inviting them to participate. The invitation described the survey as 'health related', but did not mention asthma. Those who clicked the link to start the questionnaire were asked screening questions to ensure that they had asthma and met the other inclusion criteria (Figure 1); eligible participants were then able to complete the full questionnaire. Upon completion of the survey, respondents immediately received a reward in a points-based incentive scheme. Of the 88,611 individuals who responded, the first 38,894 were excluded as soon as they failed a screening question; the process was subsequently amended to streamline recruitment and enrolment, and all other respondents $(n=49,717)$ answered all screening questions before being excluded; this technical amendment did not affect the outcome of the screening. The target survey population was 8,000; this sample size was chosen to provide a sufficiently large and robust population across the different countries. Additional respondents were not recruited once this number was achieved.

Panels met the International Organization for Standardization 20252 quality standards; multiple panels were used to reduce potential bias.

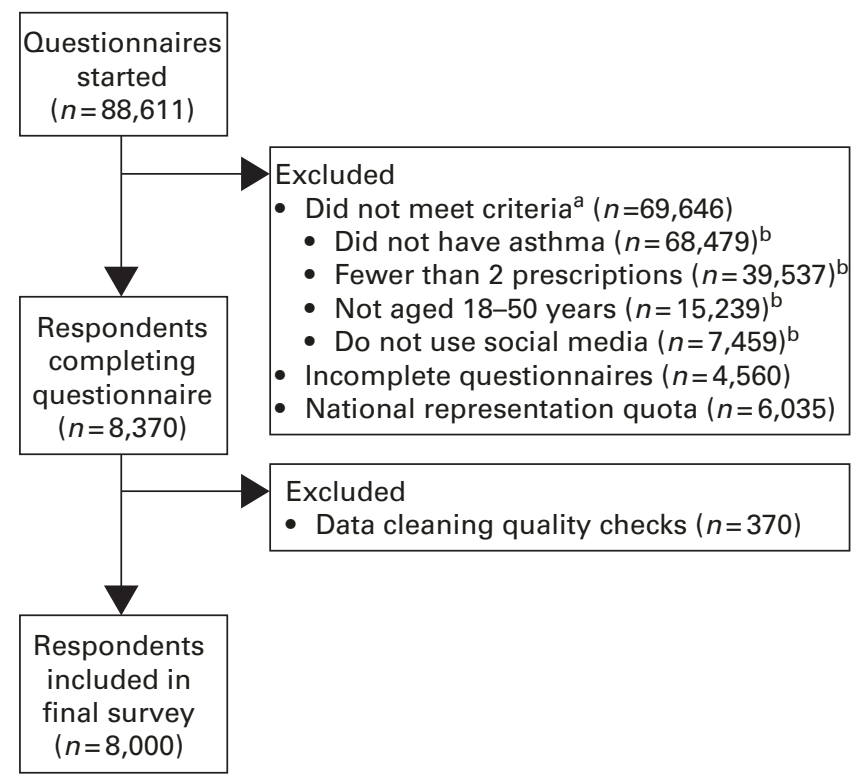

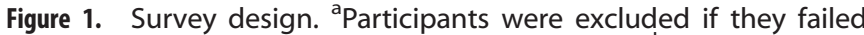
one or more screening questions (see Methods). ${ }^{b}$ Data shown for individual answers to screening questions; 49,717 respondents answered all screening questions before being screened and hence the total number of reasons for exclusion exceeds 69,646 .

Quality control measures (including cross-referencing of Internet addresses) identified respondents registered on multiple panels; these respondents were excluded.

\section{Data analysis}

Questionnaire responses were analysed for the total population; answers relating to indicators of acute exacerbations and symptoms were analysed by asthma control level and treatment type. Asthma control was assessed using the four GINA criteria based on the questions from the Helping Asthma in Real-life Patients initiative, which asked on how many days in the previous 7 days respondents had day-time symptoms, had awoken at night or had their normal activities affected by asthma, and how many times they had used a reliever inhaler. ${ }^{21}$ Respondents' perceptions of asthma were analysed by GINA-defined control level and exacerbations. Respondents were asked which treatments they were currently taking: 'reliever/rescue inhaler', 'preventer inhaler', 'combination inhaler', 'oral treatment (pill)' or 'other asthma medication'.

The relationship between indicators of asthma symptoms and exacerbations and GINA-defined control was assessed using Pearson's correlation coefficient $(r)$. Correlations of $r \geqslant 0.6$ were considered strong.

\section{RESULTS}

Respondent population

Of the 590,740 individuals invited to participate, 88,611 started answering the questionnaire (response rate 15.0\%); this response rate is broadly consistent with those for previous surveys. In total, 69,646 respondents did not meet the inclusion criteria and were excluded; the most common reason was not having asthma $(98.3 \% \quad(n=68,479)$; Figure 1). After data quality checks, 8,000 respondents were included in the final survey and data analysis and constituted the survey population (Table 1).

\section{Asthma control and symptoms}

Overall, $20.1 \%$ of respondents had controlled asthma according to the GINA criteria, $34.8 \%$ had partially controlled asthma and $45.1 \%$ 
Table 1. Respondent demographics and characteristics

\begin{tabular}{|c|c|}
\hline & $\begin{array}{c}\text { Respondents } \\
(\mathrm{N}=8,000)\end{array}$ \\
\hline \multicolumn{2}{|l|}{ Sex, n (\%) } \\
\hline Female & $4,918(61.5)$ \\
\hline Male & $3,082(38.5)$ \\
\hline Age, years & 34.7 \\
\hline \multicolumn{2}{|l|}{ Age range, years, $\mathrm{n}(\%)$} \\
\hline $18-25$ & $1,540(19.3)$ \\
\hline $26-35$ & $2,697(33.7)$ \\
\hline $36-40$ & $1,372(17.2)$ \\
\hline $41-50$ & $2,391(29.9)$ \\
\hline \multicolumn{2}{|l|}{ Country, n (\%) } \\
\hline France & $1,024(12.8)$ \\
\hline Spain & $1,020(12.8)$ \\
\hline Italy & $1,014(12.7)$ \\
\hline Germany & $1,000(12.5)$ \\
\hline UK & $1,000(12.5)$ \\
\hline Netherlands & $855(10.7)$ \\
\hline Sweden & $603(7.5)$ \\
\hline Finland & $473(5.9)$ \\
\hline Austria & $468(5.9)$ \\
\hline Belgium & $303(3.8)$ \\
\hline Norway & $240(3.0)$ \\
\hline \multicolumn{2}{|l|}{ Years since asthma diagnosis, $\mathrm{n}(\%)^{\mathrm{a}}$} \\
\hline 1 or less & $233(3.3)$ \\
\hline $2-5$ & $777(11.0)$ \\
\hline $6-10$ & $1,069(15.1)$ \\
\hline 11 or more & $5,014(70.7)$ \\
\hline Current smokers, $^{\mathrm{b}} n(\%)$ & $1,820(22.8)$ \\
\hline \multicolumn{2}{|l|}{ Co-morbidities, ${ }^{\mathrm{C}} \mathrm{n}(\%)$} \\
\hline Depression & $1,083(13.5)$ \\
\hline High BP/hypertension & $1,210(15.1)$ \\
\hline Diabetes & $870(10.9)$ \\
\hline Rheumatoid arthritis & $670(8.4)$ \\
\hline COPD & $493(6.2)$ \\
\hline Heart disease & $426(5.3)$ \\
\hline Cancer & $221(2.8)$ \\
\hline \multicolumn{2}{|l|}{ Treatment type, ${ }^{\mathrm{d}} \mathrm{n}(\%)$} \\
\hline None & $359(7.7)$ \\
\hline Reliever inhaler only & $1,419(30.3)$ \\
\hline $\begin{array}{l}\text { Single-drug preventer inhaler ( } \pm \text { reliever } \\
\text { inhaler) }\end{array}$ & $1,923(41.0)$ \\
\hline $\begin{array}{l}\text { Combination preventer inhaler }( \pm \text { reliever } \\
\text { inhaler) }\end{array}$ & $754(16.1)$ \\
\hline $\begin{array}{l}\text { Combination preventer inhaler plus oral } \\
\text { pill ( } \pm \text { reliever inhaler) }\end{array}$ & $234(5.0)$ \\
\hline
\end{tabular}

Data are shown as means unless otherwise stated.

Abbreviations: BP, blood pressure; COPD, chronic obstructive pulmonary disease.

${ }^{a} n=7,093$.

${ }^{b}$ Combines answers for respondents who described themselves as 'still smoking', as opposed to 'never smoked tobacco', 'have tried tobacco in the past, but don't currently smoke' and 'used to smoke tobacco, but don't now'.

'Self-reported by respondents as having been diagnosed by a doctor, in response to the question: 'Do you currently suffer from any of the following illnesses, which have been diagnosed by a doctor?'.

${ }^{\mathrm{d}}$ Only respondents with an identifiable treatment were included $(n=4,689)$.

had uncontrolled asthma (Table 2). Over half of the respondents had awoken at night or had symptoms that interfered with daily activities in the week before completing the survey. Overall, $44.0 \%$ of respondents reported having used oral steroids for asthma in the previous 12 months, $23.9 \%$ reported having visited an emergency department and $11.7 \%$ reported having been hospitalised overnight. Breathlessness was identified as the symptom with the greatest impact (Figure 2).

Symptoms and exacerbations across control levels Incidences of asthma symptoms and indicators of exacerbations across asthma control levels are shown in Table 2. Some respondents whose asthma was currently controlled according to the GINA criteria reported a history of acute exacerbations in the previous year: $42.3 \%$ used antibiotics, $23.7 \%$ required oral steroids, $7.4 \%$ visited an emergency department and $1.6 \%$ had been hospitalised overnight owing to asthma in the 12 months before the survey.

Symptoms and indicators of acute exacerbations across treatment levels

Table 3 presents GINA-defined levels of asthma control, incidence of symptoms and indicators of acute exacerbations stratified by treatment level. Symptoms tended to be more common among respondents prescribed maintenance therapy than among those prescribed only a reliever inhaler (Table 3 ). The proportion reporting indicators of acute exacerbations increased consistently with treatment level. Notably, across all treatment levels, half of the respondents had been prescribed a course of antibiotics owing to their asthma and more than one-quarter had required oral steroids in the previous 12 months. High levels of reliever inhaler use ( $\geqslant 10$ times in the previous 7 days) were most common among respondents prescribed a combination preventer inhaler.

Respondents' perceptions of asthma

Respondents' perceptions of their asthma symptoms and control are summarised in Table 4. Most did not regard themselves as 'sick', and many stated that they ignored their asthma to 'feel normal and fit in'. More than $80 \%$ of respondents considered their asthma to be controlled and over two-thirds did not regard their condition as serious, even among those whose asthma was uncontrolled according to the GINA criteria (Table 5). Similarly, more than $80 \%$ of respondents who had experienced acute exacerbations (oral steroid use, emergency department visits or hospitalisations) in the previous year regarded their asthma as controlled. Of those who considered their asthma controlled, $55.5 \%$ had had symptoms that interfered with normal activities and $52.5 \%$ had awoken at night owing to asthma in the previous week. Moreover, of those who regarded their asthma as not serious, $19.5 \%$ reported an asthma-related emergency department visit in the previous year.

Attitudes towards asthma and its management

The majority of respondents were fairly or very confident about managing their asthma (91.7\%) and felt they had 'excellent' or 'good' knowledge about its treatment (75.3\%). Over half of any respondents who stated that they had a preventer inhaler did not use it every day as prescribed (Figure 3). The most common reasons selected for non-adherence (base, $n=1,401$ ) were not seeing the need to take it (50.0\%) or forgetting (18.6\%). More than one-quarter of respondents felt embarrassed about their inhaler, and two out of five considered it a nuisance (Figure 4). Overall, $52.7 \%$ of respondents had not had their inhaler technique checked by an HCP in the previous 12 months.

\section{Sources of asthma information}

Overall, $78.5 \%$ of respondents stated that they would consult their HCP for information about asthma (Figure 5); moreover, $60.7 \%$ 
Table 2. Indicators of asthma symptoms and exacerbations overall and by GINA-defined control levels

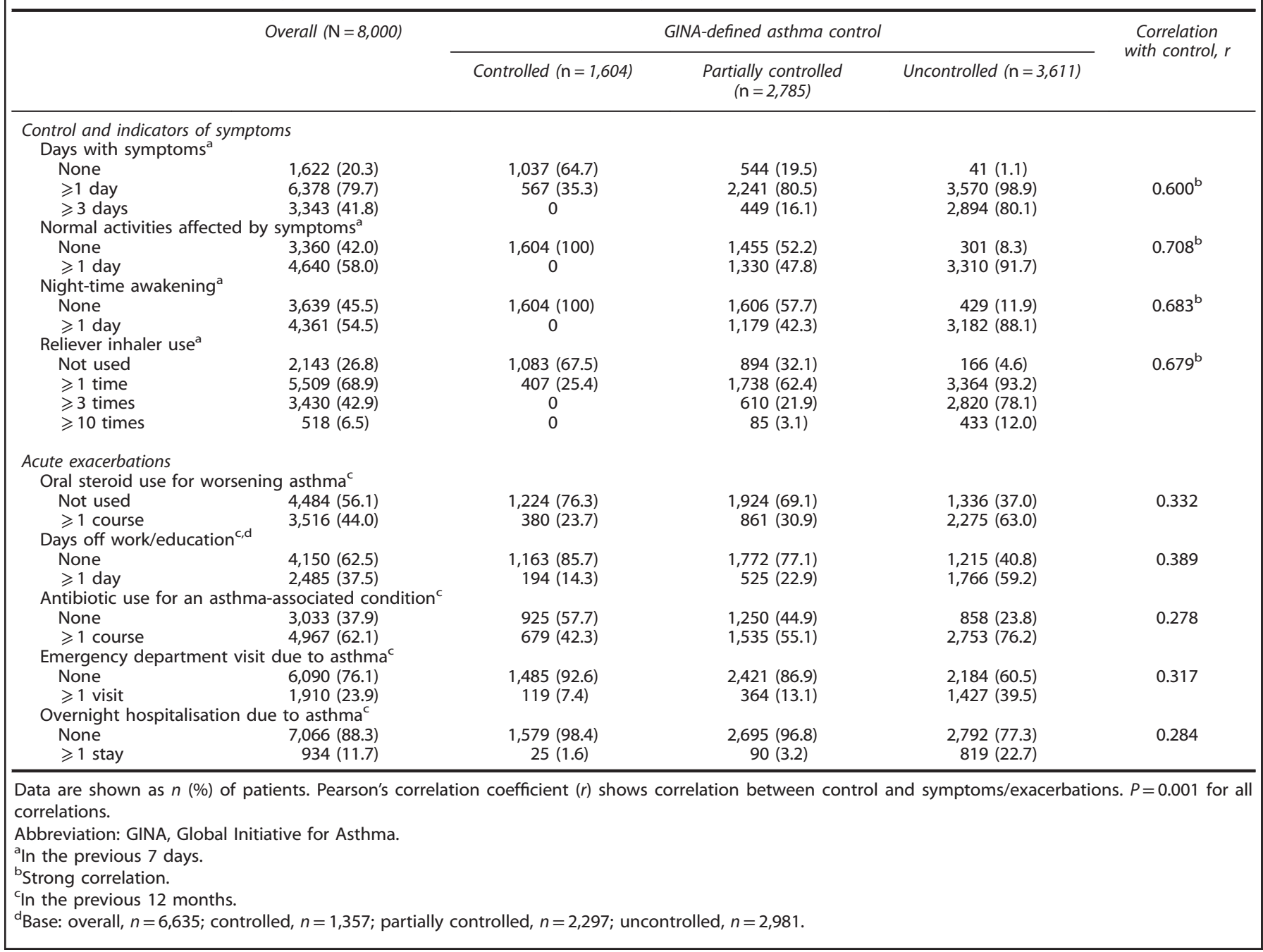

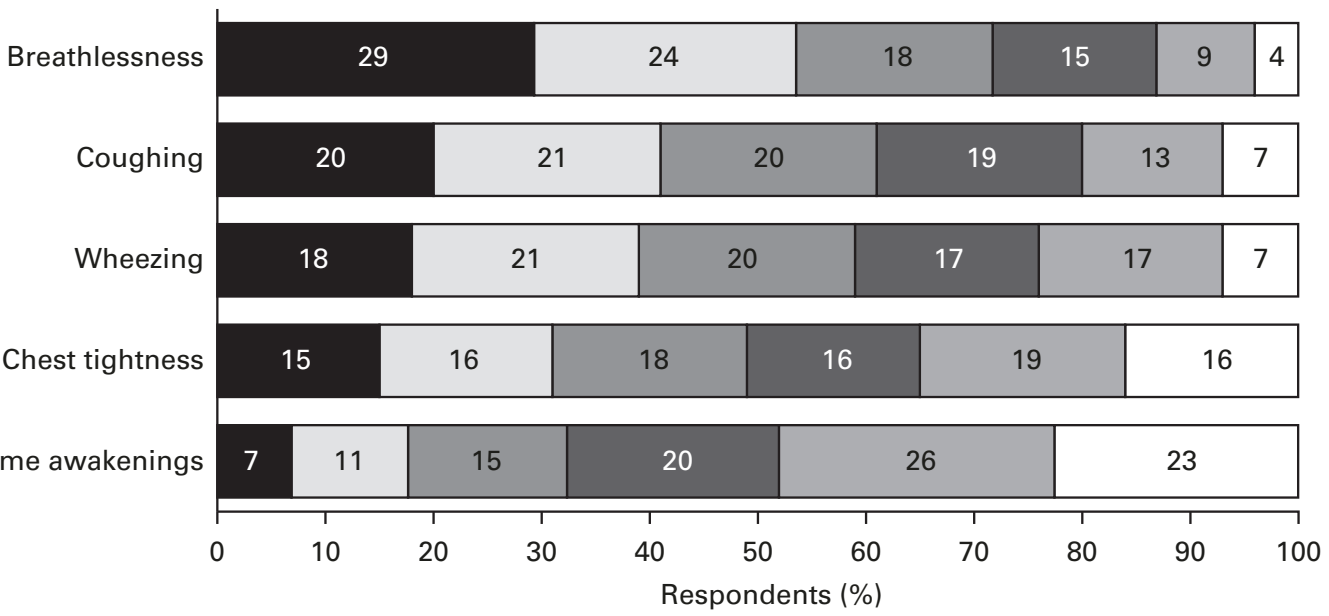

Ranked $1 \quad \square$ Ranked $2 \square$ Ranked 3 $\square$ Ranked $4 \quad \square$ Ranked $5 \quad \square$ This doesn't affect me

Figure 2. Asthma symptoms with the greatest impact on respondents' lives for the overall population. Q. Which asthma symptoms do you find affect you most? Place in order, with 1 having the most impact on your life and 5 the least. Base: $N=8,000$. Numbers shown are percentages. 
Table 3. Asthma control and indicators of symptoms and exacerbations by treatment level

\begin{tabular}{|c|c|c|c|c|}
\hline & $\begin{array}{l}\text { Reliever only } \\
(\mathrm{n}=1,419)\end{array}$ & $\begin{array}{l}\text { Single-drug preventer } \\
\text { inhaler }(\mathrm{n}=1,923)\end{array}$ & $\begin{array}{l}\text { Combination preventer } \\
\text { inhaler }(\mathrm{n}=754)\end{array}$ & $\begin{array}{c}\text { Combination preventer inhaler } \\
\text { plus oral pill }(\mathrm{n}=234)\end{array}$ \\
\hline \multicolumn{5}{|c|}{ Control and indicators of symptoms } \\
\hline Controlled & $408(28.8)$ & $465(24.2)$ & $165(21.9)$ & $40(17.1)$ \\
\hline Partially controlled & 594 (41.9) & 700 (36.4) & 278 (36.9) & 79 (33.8) \\
\hline Uncontrolled & $417(29.4)$ & 758 (39.4) & $311(41.2)$ & $115(49.1)$ \\
\hline \multicolumn{5}{|c|}{ Normal activities affected by symptoms ${ }^{a}$} \\
\hline$\geqslant 3$ days & $187(13.2)$ & $318(16.5)$ & $160(21.2)$ & $67(28.6)$ \\
\hline \multicolumn{5}{|l|}{ Days with symptoms ${ }^{a}$} \\
\hline None & $370(26.1)$ & $417(21.7)$ & $164(21.8)$ & $37(15.8)$ \\
\hline$\geqslant 1$ day & 1,049 (73.9) & $1,506(78.3)$ & $590(78.2)$ & $197(84.2)$ \\
\hline$\geqslant 3$ days & $389(27.4)$ & $724(37.6)$ & $340(45.1)$ & $115(49.1)$ \\
\hline \multicolumn{5}{|l|}{ Night-time awakening ${ }^{a}$} \\
\hline$\geqslant 1$ times & $871(61.4)$ & $1,297(67.4)$ & $501(66.4)$ & $172(73.5)$ \\
\hline$\geqslant 3$ times & $430(30.3)$ & $786(40.9)$ & $326(43.2)$ & $112(47.9)$ \\
\hline$\geqslant 10$ times & $38(2.7)$ & $139(7.2)$ & $64(8.5)$ & $23(9.8)$ \\
\hline \multicolumn{5}{|c|}{ Acute exacerbations } \\
\hline \multicolumn{5}{|c|}{ Antibiotic use for an asthma-associated condition $\mathrm{b}$} \\
\hline 0 & $698(49.2)$ & $860(44.7)$ & $334(44.3)$ & $69(29.5)$ \\
\hline$\geqslant 1$ course & $721(50.8)$ & $1,063(55.3)$ & $420(55.7)$ & $165(70.5)$ \\
\hline \multicolumn{5}{|c|}{ Oral steroid use for worsening asthma ${ }^{b}$} \\
\hline 0 & 1,049 (73.9) & $1,362(70.8)$ & $455(60.3)$ & $86(36.8)$ \\
\hline$\geqslant 1$ course & $370(26.1)$ & $561(29.2)$ & $299(39.7)$ & $148(63.2)$ \\
\hline \multicolumn{5}{|c|}{ Emergency department visit due to asthma ${ }^{\mathrm{b}}$} \\
\hline 0 & $1,243(87.6)$ & $1,650(85.8)$ & $614(81.4)$ & $164(70.1)$ \\
\hline
\end{tabular}

Table 4. Patients' perceptions of their asthma

\begin{tabular}{|c|c|c|c|c|}
\hline & Overall $(\mathrm{N}=8,000)$ & $\begin{array}{l}\text { Controlled } \\
(\mathrm{n}=1,604)\end{array}$ & $\begin{array}{l}\text { Partially controlled } \\
\qquad(\mathrm{n}=2,785)\end{array}$ & $\begin{array}{l}\text { Uncontrolled } \\
(\mathrm{n}=3,611)\end{array}$ \\
\hline \multicolumn{5}{|l|}{ Respondents who agree with the following statements, $\mathrm{n}$ (\%) } \\
\hline Don't label me as a person who is sick ${ }^{a}$ & $6,558(82.0)$ & $1,400(87.3)$ & 2,322 (83.4) & $2,836(78.5)$ \\
\hline $\begin{array}{l}\text { I am in better health than other people my age/l have a } \\
\text { similar level of health to other people my age }\end{array}$ & 5,647 (70.6) & $1,323(82.5)$ & $2,057(73.9)$ & $2,267(62.8)$ \\
\hline $\begin{array}{l}\text { I ignore my asthma and its symptoms so I can feel normal } \\
\text { and fit in with my friends/peers }{ }^{\mathrm{a}}\end{array}$ & $3,420(42.8)$ & $622(38.8)$ & $1,197(43.0)$ & $1,601(44.3)$ \\
\hline \multicolumn{5}{|l|}{$\begin{array}{l}\text { Abbreviation: GINA, Global Initiative for Asthma. } \\
\text { a'Responses were combined for 'tend to agree' and 'strongly agree'. } \\
\text { bResponses to both statements were combined. }\end{array}$} \\
\hline
\end{tabular}


Table 5. Patients' perceptions of asthma control for the overall population and by GINA-defined control levels and exacerbations

\begin{tabular}{|c|c|c|c|c|c|c|c|}
\hline & \multicolumn{4}{|c|}{ GINA-defined asthma control } & \multicolumn{3}{|c|}{ Acute exacerbations ${ }^{\mathrm{a}}$} \\
\hline & Overall $(\mathrm{N}=8,000)$ & $\begin{array}{l}\text { Controlled } \\
(\mathrm{n}=1,604)\end{array}$ & $\begin{array}{l}\text { Partially } \\
\text { controlled } \\
(\mathrm{n}=2,785)\end{array}$ & $\begin{array}{l}\text { Uncontrolled } \\
(\mathrm{n}=3,611)\end{array}$ & $\begin{array}{l}\text { Oral steroid } \\
(\mathrm{n}=3,516)\end{array}$ & $\begin{array}{c}\text { Emergency } \\
\text { department visits } \\
(\mathrm{n}=1,910)\end{array}$ & $\begin{array}{l}\text { Hospitalisations } \\
\quad(\mathrm{n}=934)\end{array}$ \\
\hline \multicolumn{8}{|c|}{ Perception of asthma control } \\
\hline $\begin{array}{l}\text { Not } \\
\text { controlled }\end{array}$ & $757(9.5)$ & $42(2.6)$ & $127(4.6)$ & $588(16.3)$ & 417 (11.9) & $288(15.1)$ & $164(17.6)$ \\
\hline \multicolumn{8}{|c|}{ Perception of asthma seriousness } \\
\hline Not serious & $6,682(83.5)$ & $1,572(98.0)$ & $2,587(92.9)$ & $2,523(69.9)$ & $2,636(75.0)$ & $1,300(68.1)$ & $541(57.9)$ \\
\hline Serious & $1,318(16.5)$ & $32(2.0)$ & $198(7.1)$ & $1,088(30.1)$ & $880(25.0)$ & $610(31.9)$ & $393(42.1)$ \\
\hline \multicolumn{8}{|c|}{ Concern about asthma } \\
\hline $\begin{array}{l}\text { Not } \\
\text { concerned }\end{array}$ & $5,992(74.9)$ & $1,532(95.5)$ & $2,354(84.5)$ & $2,106(58.3)$ & $2,240(63.7)$ & $1,108(58.0)$ & $477(51.1)$ \\
\hline
\end{tabular}

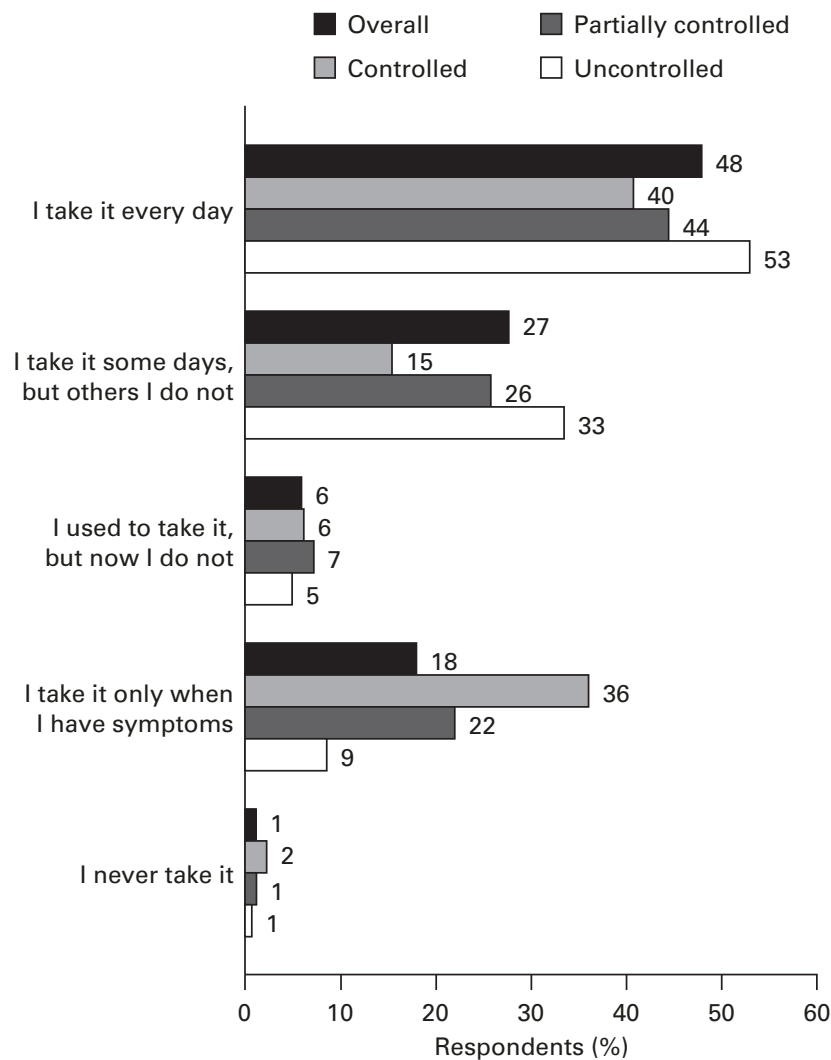

Figure 3. Daily use of preventer medication. Q: Which statement best describes how you take your regular asthma treatment? This is your preventer inhaler, which is usually brown, orange or red. Base: respondents taking a preventer inhaler (overall: $n=3,481$; Global Initiative for Asthma-defined controlled: $n=620$; partially controlled: $n=1,171$; uncontrolled: $n=1,690$ ).

said they would also use online sources-including search engines $(43.6 \%)$, specific disease- or health-related websites $(30.0 \%)$ and social media such as Facebook (4.1\%) and Twitter (1.5\%).

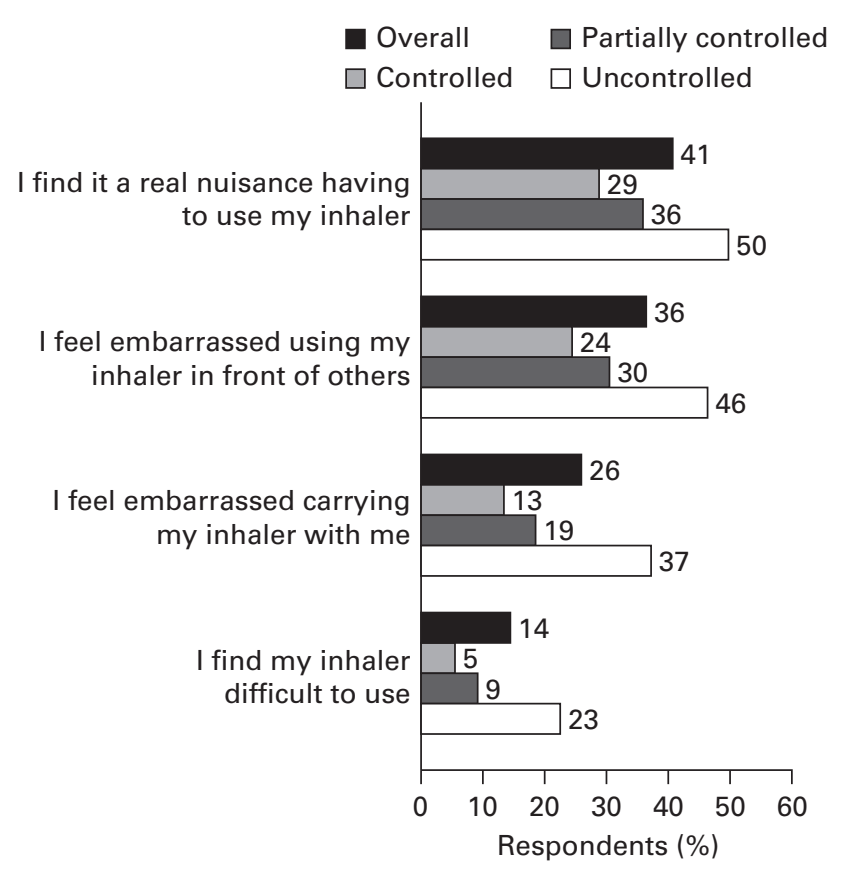

Figure 4. Respondents' attitudes towards their inhaler. Q: To what extent do you agree with the following statements? Data shown for strongly agree plus tend to agree. Base overall: $n=8,000$; Global Initiative for Asthma-defined controlled: $n=1,604$; partially controlled: $n=2,785$; uncontrolled: $n=3,611$.

\section{DISCUSSION}

Main findings

Overall, these data from the REALISE survey indicate that the level of GINA-defined asthma control remains low, with only one-fifth of respondents having controlled asthma. The incidence of symptoms and acute exacerbations was high; almost half of the respondents reported that they had required oral steroids for asthma in the previous year and almost one-quarter had visited the emergency department. Indeed, many respondents whose asthma was 


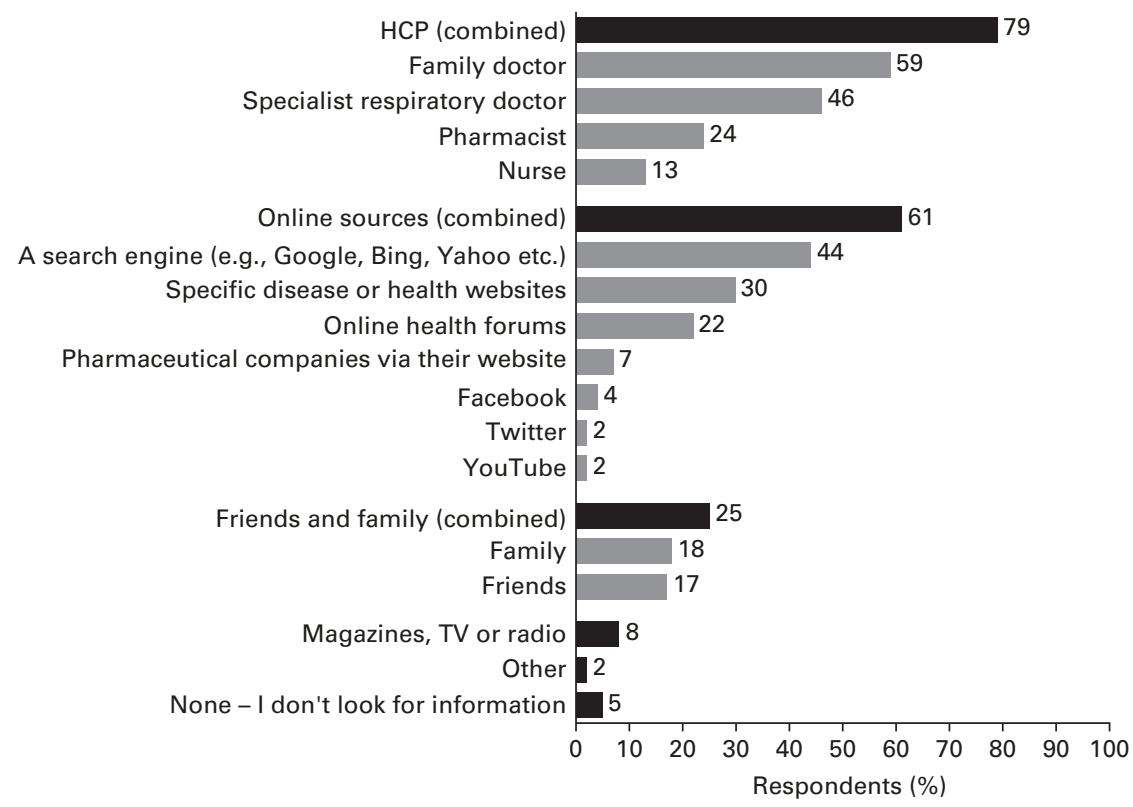

Figure 5. Sources of information about asthma. Q: If you were to look for information about asthma, which of the following would you use? Combined $=$ all respondents who selected at least one answer from the list of possible options. Base: $N=8,000$.

controlled at the time of the survey according to the GINA criteria reported a history of acute exacerbations over the previous year. Most respondents did not recognise symptoms as indicators of poor control, suggesting a continuing disconnection between patients' perceptions of control and guideline-defined control.

Strengths and limitations of this study

The REALISE survey is one of the largest surveys of patients' attitudes to asthma and its management in Europe to date, conducted in a population using the Internet and social media. As for any survey of this kind, however, there are some limitations. The main aim of REALISE was to provide a broad view of asthma control and patient attitudes across Europe as a whole. All data were analysed for the whole study population; however, there was some country-specific variation among respondents from the different countries included.22 All data were reported by the respondents and could not be clinically verified, and inaccurate responses due to poor recall cannot be excluded. This survey assessed patients aged $18-50$ years who used social media, and this group may not be fully representative of the wider patient population. This study was not designed to compare asthma control among respondents who use social media with those who do not; it might be interesting to observe any effect of social media on asthma management in future surveys. The mean age of respondents is lower than that of patients with asthma in previous European appraisals in clinical practice, such as the European National Health and Wellness Survey. ${ }^{5,23}$ We believe, however, that the REALISE respondent population is broadly consistent with asthma populations reported in other studies. The proportion of females was comparable to those reported elsewhere (including the European Community Respiratory Health Survey and Asthma Insights and Reality in Europe), 5,19,23,24 as were the proportions of current smokers and respondents prescribed controller medication. ${ }^{5,23}$ Moreover, the reported incidences of emergency department visits and hospitalisations due to asthma were similar to those in the National Health and Wellness Survey. ${ }^{5}$ Co-morbidities were self-reported by respondents and not clinically verified. We sought to compare the levels of co-morbidities with other, comparable survey populations, but these were frequently not reported. ${ }^{5,17-19,22}$ Overall, the level of self-reported co-morbidities was relatively high, especially for a young population. Depression was the most frequent comorbidity among REALISE respondents (prevalence, 13.5\%), although this was observed to a greater degree in the Health and Wellbeing Study $(21-29 \%)^{5}$ In the present survey, respondents were recruited from different consumer panels and, in some cases, through press advertising; however, this is unlikely to have introduced systematic bias.

Interpretation of findings in relation to previously published work Overall, the findings of REALISE are in agreement with previous initiatives. Our present survey offers the largest pan-European appraisal of GINA-defined control, incidence of symptoms and exacerbations, and insights into patient attitudes and understanding of the disease (Table 6). The observed incidences of uncontrolled asthma and symptoms are broadly consistent with those reported in previous surveys of patients with asthma, $7,16-20,25$ underlining the validity of this study. In a recent European survey, $54 \%$ of patients had asthma that was not well controlled, ${ }^{5}$ compared with $45 \%$ of respondents with uncontrolled asthma in the present survey. In the 2005 International Asthma Patient Insight Research survey, conducted in a population using combination therapy, the rate of uncontrolled asthma was $51 \%{ }^{7}$ Notably, in the current survey, the proportion of patients in the corresponding subset (those prescribed a combination preventer inhaler) with uncontrolled asthma was lower (41\%), suggesting that, although asthma control remains low overall, there may have been a slight improvement in recent years. ${ }^{7}$ Patients using the Internet may benefit from access to online information sources about asthma. Interestingly, a study has shown that asthma control may be improved by online selfmanagement strategies-including the monitoring of control, treatment advice and online education. ${ }^{26}$

Implications for future research, policy and practice

Frequent reliever inhaler use was notable; more than $40 \%$ of respondents had used their reliever three or more times in the previous week, and frequent use ( $\geqslant 10$ times in the previous week) was highest in those prescribed a combination preventer inhaler. This may reflect high levels of uncontrolled asthma, but could also 
Table 6. Other European surveys and studies of patients with asthma

\begin{tabular}{|c|c|c|c|c|c|c|c|}
\hline Study name & $\begin{array}{l}\text { Number of } \\
\text { countries }^{\mathrm{a}}\end{array}$ & $\begin{array}{c}\text { Number of } \\
\text { patients }\end{array}$ & Age, years & Survey design & $\begin{array}{l}\text { Prevalence of } \\
\text { uncontrolled } \\
\text { asthma }\end{array}$ & $\begin{array}{l}\text { Experienced } \\
\text { symptoms }\end{array}$ & $\begin{array}{l}\text { Rescue medication } \\
\text { use }\end{array}$ \\
\hline $\begin{array}{l}\text { European National } \\
\text { Health and Wellness } \\
\text { Survey }^{5} \text { ( } 2010 \text { data) }\end{array}$ & 5 & 3,848 & 18 and above & $\begin{array}{l}\text { Repeated cross- } \\
\text { sectional survey }\end{array}$ & $\begin{array}{l}54 \% \text { ('not well- } \\
\text { controlled') }\end{array}$ & $\begin{array}{l}\text { NR as percentage } \\
\text { of patients }\end{array}$ & $\begin{array}{l}\sim 75 \%>2 \text { times } \\
\text { per week (not well- } \\
\text { controlled } \\
\text { population) }\end{array}$ \\
\hline $\begin{array}{l}\text { The Living and } \\
\text { Breathing study }^{20}\end{array}$ & 1 & 517 & $14-65$ & $\begin{array}{l}\text { Quantitative face- } \\
\text { to-face interview }\end{array}$ & NR & $\begin{array}{l}66 \% \text { ( }>2 \text { times } \\
\text { per week) }\end{array}$ & $32 \%$ daily \\
\hline $\begin{array}{l}\text { Global Asthma } \\
\text { Insights and Reality } \\
\text { Survey }^{16}\end{array}$ & 7 & 2,803 & $\begin{array}{l}\text { Children }(<16) \\
\text { and adults }\end{array}$ & $\begin{array}{l}\text { Telephone } \\
\text { questionnaire }\end{array}$ & NR & $\begin{array}{l}56 \% \text { (in the } \\
\text { previous } 4 \text { weeks) }\end{array}$ & NR \\
\hline $\begin{array}{l}\text { International } \\
\text { Control of Asthma } \\
\text { Symptoms }\end{array}$ & $7^{\mathrm{b}}$ & 802 & 16 and above & $\begin{array}{l}\text { Computer-aided } \\
\text { telephone } \\
\text { interview }\end{array}$ & $\begin{array}{l}82 \% \text { ('absence of } \\
\text { control') }\end{array}$ & $\begin{array}{l}74 \% \text { (in the } \\
\text { previous } 8 \text { weeks) }\end{array}$ & $\begin{array}{l}62 \%(>1 \text { use in the } \\
\text { previous } 8 \text { weeks) }\end{array}$ \\
\hline $\begin{array}{l}\text { Asthma Insight and } \\
\text { Management in } \\
\text { Europe and Canada } \\
\text { (EUCAN AIM) } \\
\text { survey }^{25}\end{array}$ & 5 & 2,019 & $\begin{array}{l}\text { Adolescents } \\
(12-17) \text { and adults }\end{array}$ & $\begin{array}{l}\text { Telephone } \\
\text { interview }\end{array}$ & $12-35 \%{ }^{c}$ & $\begin{array}{l}13-29 \%^{c} \text { (every } \\
\text { day or most days } \\
\text { in the previous } \\
4 \text { weeks) }\end{array}$ & $\begin{array}{l}31-56 \%^{c} \text { (>1 use } \\
\text { per week, over the } \\
\text { past year) }\end{array}$ \\
\hline UK asthma survey ${ }^{38}$ & 1 & 1,083 & 18 and above & $\begin{array}{l}\text { Online } \\
\text { questionnaire } \\
\text { survey }\end{array}$ & NR & $\begin{array}{l}65 \% \text { (in the } \\
\text { past } 2 \text { years) }\end{array}$ & $41 \%(\geqslant 1 /$ day $)$ \\
\hline $\begin{array}{l}\text { Understanding } \\
\text { patients with } \\
\text { asthma and COPD }\end{array}$ & 5 & 1,022 & 18 and above & $\begin{array}{l}\text { Online } \\
\text { questionnaire } \\
\text { survey }\end{array}$ & $38 \%(A C Q>1.5)$ & NR & $\begin{array}{l}58 \% \text { ( }>1-2 \text { most } \\
\text { days) }\end{array}$ \\
\hline
\end{tabular}

indicate an over-reliance on rescue medication, suggesting that patients do not recognise reliever use as a sign of deteriorating asthma and that their medication may require adjustment. ${ }^{7}$

Our survey also found a high incidence of oral steroid use, emergency department visits and hospitalisations over the 12 months before the survey, even among those whose asthma was controlled at the time of the survey. These indicators are consistent with the American Thoracic Society/European Respiratory Society Statement definition of severe exacerbations in clinical trials, ${ }^{27}$ demonstrating that exacerbations in clinical practice remain common and are a serious concern. Currently controlled asthma does not preclude future exacerbations. Accordingly, in addition to a patient's current level of symptoms and asthma control, it is important to assess their exacerbation risk. ${ }^{9}$ Indeed, international guidelines state that the joint aims of asthma management should be to achieve asthma control and reduce exacerbation risk. Our findings may suggest a need to improve the assessment of control and patients' risk for future exacerbations.

GINA guidelines recommend a stepwise approach to asthma management. $^{2}$ The proportion of respondents with uncontrolled asthma was high across all treatment levels, which may indicate under-use, inappropriate use or under-prescription of therapies; this highlights the need for HCPs to supervise treatment use more closely, provide hands-on advice and guidance, and empower patients through education to achieve better self-management of their asthma.

The data also provide insights into patient attitudes to asthma and its treatment. Most respondents did not want to be labelled as sick; the majority also regarded their asthma as controlled and not serious, even among respondents with uncontrolled asthma, highlighting a disconnection between patients' perceptions of their asthma and guideline-defined levels of control. This disconnect has been reported before, and it is worrying that there has been little apparent improvement; ${ }^{6,19,20,28}$ in a previous survey, up to half of the patients with severe persistent symptoms considered their asthma to be controlled. ${ }^{6,19}$

These findings together show a need to ensure that asthma is accurately assessed in clinical practice, and to improve patients' understanding so that symptoms and exacerbations are recognised and acted upon. The disconnection between patientperceived and guideline-defined control may be partly due to different aspirations of patients and HCPs, as well as different definitions of 'control' between patients and variations in assessments from clinical questionnaires. For patients, asthma control may be most easily understood as managing exacerbation risk, rather than as achieving a predefined threshold of symptom control. In addition, successful asthma management requires a good partnership between patients and $\mathrm{HCPs}^{28}$ a shared language and understanding is vital. Training HCPs in patient-centred communication skills can help optimise asthma management in primary care. ${ }^{29}$

In clinical practice, prescriptions are often initiated based on limited information gained from short conversations during consultations. However, asthma control should be assessed using standardised tools such as the Asthma Control Questionnaire or the Asthma Control Test, which can potentially improve the assessment of control in a reproducible, objective way. ${ }^{2}$

Non-adherence and poor inhaler technique are associated with suboptimal asthma control. ${ }^{30-32}$ It is concerning that $\sim 50 \%$ of respondents reported that they did not take their maintenance therapy as prescribed, and fewer than half had had their inhaler technique checked by an HCP in the previous year. Many patients frequently use their inhaler incorrectly; ${ }^{33-35}$ however, training can improve control. In a recent study, the proportion of patients with optimal inhaler technique rose from 24 to $79 \%$ following training, leading to significant increases in asthma control scores. ${ }^{36}$ For effective instruction the trainer must also be competent in using the device, ${ }^{30}$ unfortunately, some HCPs are not aware of optimal inhaler technique. ${ }^{37}$ 
The Internet may support patient self-management of chronic conditions. ${ }^{26}$ Notably, over half of the respondents in the present survey stated that they would use online sources for information about their asthma; providing patients with access to reliable websites may thus increase their level of understanding and help improve asthma control. ${ }^{18,26}$

This report presents the first set of results from the REALISE survey. The large size of the population (which included 240-1,024 respondents from each country) and the diversity of the participating countries support further analyses, including assessment of variations in asthma control and treatment across the countries. The survey also gathered a large amount of novel information on patients' attitudes to asthma. This could be used to analyse patients' behaviour and attitudes to online sources for information about asthma; the data will be explored to determine whether different patient types exist and whether such information could help develop tailored asthma management strategies.

\section{CONCLUSIONS}

Asthma control in Europe remains poor, and symptoms and exacerbations are common across all treatment levels. Many patients with asthma do not regard themselves as sick and are not concerned about their condition, believing it to be controlled; many individuals do not associate symptoms with poor control. Hence, there remains a marked discrepancy between patientperceived and guideline-defined asthma control. There is a clear need to assess patients' control, risk and inhaler technique, and to ensure that they are prescribed, and take, appropriate treatments. Educating patients will help improve their understanding of asthma and enable them to work with their HCP to manage their disease.

\section{ACKNOWLEDGEMENTS}

We thank Dr Peter Haidl (Schmallenberg, Germany) and Professor Chantal RaherisonSemjen (Bordeaux, France) for their advice and input on the survey questions. We are also grateful to Weber Shandwick (London, UK) for assistance in developing and running the survey, Incite Marketing Planning Ltd (London, UK) for support in the development of the questionnaire and analysing the results, and Dr Mark Rolfe and Dr Andreas Leidenroth (Oxford PharmaGenesis, Oxford, UK) for medical writing support.

\section{CONTRIBUTIONS}

All authors contributed to the conception and design of the survey, interpretation of the data, and development of the flow, outline and content of the manuscript; the authors reviewed each draft of the full manuscript and approved the final version. The authors take full responsibility for the content of the article and act as guarantors.

\section{COMPETING INTERESTS}

DP has acted as a consultant and board member for Almirral, AstraZeneca, Boehringer Ingelheim, Chiesi, GlaxoSmithKline, Meda Pharma, Merck, Mundipharma, Napp, Novartis, Nycomed, Pfizer, Sandoz and Teva. He or his research team has received grants and support for research in respiratory disease from the following organisations in the past 5 years: Aerocrine, AstraZeneca, Boehringer Ingelheim, Chiesi, GlaxoSmithKline, Merck, Mundipharma, Novartis, Nycomed, Orion, Pfizer, Teva and the UK National Health Service. Grants/ grants pending: Aerocrine, AstraZeneca, Boehringer Ingelheim, Chiesi, GlaxoSmithKline, Merck, Mundipharma, Novartis, Nycomed, Orion, Pfizer, Takeda, Teva and the UK National Health Service. Payments for lectures/ speaking: Activaero, Almirral, AstraZeneca, Boehringer Ingelheim, Chiesi, Cipla, GlaxoSmithKline, Kyorin, Novartis, Merck, Mundipharma, Pfizer, Takeda and Teva. Payment for manuscript preparation: Merck, Mundipharma and Teva. Stock/stock options: shares in AKL Ltd, which produces phytopharmaceuticals; owner of $80 \%$ of Research in Real Life and its subsidiary social enterprise
Optimum Patient Care. Payment for travel/accommodation/meeting expenses: Aerocrine, Boehringer Ingelheim, Mundipharma, Napp, Novartis and Teva. MF has received reimbursement for travel and accommodation from Amirall UK and Novartis AG. Education for Health received honoraria from Almirall, Boehringer, Ingelheim, Novartis AG and Novartis UK for advisory boards attended by MF. It also received educational grants from Almirall, Chiesi and TEVA, and grants for research in the last 5 years from Abbott Laboratories, AstraZeneca, Novartis AG, Pfizer and UCB. TvdM has acted as a consultant and board member for Almirral, AstraZeneca, Boehringer Ingelheim, Chiesi, GlaxoSmithKline, Mundipharma, Novartis and Teva, and as a consultant for MSD. Grants/grants pending: His research department at the University of Groningen has received grants and support for research in respiratory disease from the following organisations in the past 5 years: AstraZeneca, Boehringer Ingelheim, Chiesi, GlaxoSmithKline, Lung Foundation Netherlands, Merck, Mundipharma, Novartis, Nycomed and Stichting Astma Bestrijding. Payments for lectures/speaking: Almirral, AstraZeneca, Boehringer Ingelheim, Chiesi, Cipla, GlaxoSmithKline, Kyorin, Merck, Mundipharma, Novartis and Teva. Payment for travel/accommodation/meeting expenses: Boehringer Ingelheim, Mundipharma, Novartis and Teva.

\section{FUNDING}

Funding for the survey and medical writing support was provided by Mundipharma International.

\section{REFERENCES}

1 Lozano R, Naghavi M, Foreman K, Lim S, Shibuya K, Aboyans V et al. Global and regional mortality from 235 causes of death for 20 age groups in 1990 and 2010: a systematic analysis for the Global Burden of Disease Study 2010. Lancet 2012; 380: 2095-2128.

2 GINA Report, Global Strategy for Asthma Management and Prevention, 2012. http://www.ginasthma.org/uploads/users/files/GINA_Report_2011.pdf (accessed 18 June 2012).

3 The European Severe Asthma Survey, 2005. http://www.efanet.org/wp-content/ documents/SASSurveyFactSheet.pdf (accessed 6 March 2013).

4 Lung Health in Europe-Facts and figures. Abbreviated version of the European Lung White Book, 2003. http://www.european-lung-foundation.org/715european-lung-foundation-elf-european-respiratory-society.htm (accessed March 2013).

5 Demoly P, Annunziata K, Gubba E, Adamek L. Repeated cross-sectional survey of patient-reported asthma control in Europe in the past 5 years. Eur Respir Rev 2012; 21: 66-74.

6 Rabe KF, Vermeire PA, Soriano JB, Maier WC. Clinical management of asthma in 1999: the Asthma Insights and Reality in Europe (AIRE) study. Eur Respir J 2000; 16: 802-807.

7 Partridge MR, van der Molen T, Myrseth SE, Busse WW. Attitudes and actions of asthma patients on regular maintenance therapy: the INSPIRE study. BMC Pulm Med 2006; 6: 13.

8 Demoly P, Gueron B, Annunziata K, Adamek L, Walters RD. Update on asthma control in five European countries: results of a 2008 survey. Eur Respir Rev 2010; 19: 150-157.

9 Sims EJ, Price D, Haughney J, Ryan D, Thomas M. Current control and future risk in asthma management. Allergy Asthma Immunol Res 2011; 3: 217-225.

10 Bateman E, Harrison TW, Quirce S, Reddel HK, Buhl R, Humbert M et al. Overall asthma control achieved with budesonide/formoterol maintenance and reliever therapy for patients on different treatment steps. Respir Resh 2011; 12: 38.

11 Price D, Ali M, Burden A, Chisholm A, Lee AJ, Kemp L et al. Effectiveness of combination therapies: real-world versus randomized controlled trials. Prim Care Respir J 2010; 19: A13 (abstract 48).

12 Pedersen S. From asthma severity to control: a shift in clinical practice. Prim Care Respir J 2010; 19: 3-9.

13 Bateman ED, Boushey HA, Bousquet J, Busse WW, Clark TJ, Pauwels RA et al. Can guideline-defined asthma control be achieved? The Gaining Optimal Asthma ControL study. Am J Respir Crit Care Med 2004; 170: 836-844.

14 Bjermer L. Evidence-based recommendations or "Show me the patients selected and I will tell you the results". Respir Med 2006; 100(Suppl 1): S17-S21.

15 Braunholtz DA, Edwards SJ, Lilford RJ. Are randomized clinical trials good for us (in the short term)? Evidence for a "trial effect". J Clin Epidemiol 2001; 54: 217-224.

16 Rabe KF, Adachi M, Lai CK, Soriano JB, Vermiere PA, Weiss KB et al. Worldwide severity and control of asthma in children and adults: the global asthma insights and reality surveys. J Allergy Clin Immunol 2004; 114: 40-47. 
17 Bellamy D, Harris T. Poor perceptions and expectations of asthma control: results of the International Control of Asthma Symptoms (ICAS) survey of patients and general practitioners. Prim Care Respir J 2005; 14: 252-258.

18 Partridge MR, Dal Negro RW, Olivieri D. Understanding patients with asthma and COPD: insights from a European study. Prim Care Respir J 2011; 20: 315-323.

19 Vermeire PA, Rabe KF, Soriano JB, Maier WC. Asthma control and differences in management practices across seven European countries. Respir Med 2002; 96 : 142-149.

20 Haughney J, Barnes G, Partridge M, Cleland J. The Living \& Breathing Study: a study of patients' views of asthma and its treatment. Prim Care Respir J 2004; 13 . 28-35.

21 iHARP: initiative Helping Asthma in Real-life Patients. http://iharp.org/ (accessed 3 March 2013).

22 Fletcher M, Van der Molen T, Price D. Differences in Asthma Control and Management in Europe. European Respiratory Society Annual Congress. Oral presentation, Barcelona, Spain, 7-11 September 2013.

23 Herland K, Akselsen JP, Skjonsberg OH, Bjermer L. How representative are clinical study patients with asthma or COPD for a larger "real life" population of patients with obstructive lung disease? Respir Med 2005; 99: 11-19.

24 Cazzoletti L, Marcon A, Janson C, Corsico A, Jarvis D, Pin I et al. Asthma control in Europe: a real-world evaluation based on an international populationbased study. J Allergy Clin Immunol 2007; 120: 1360-1367.

25 Asthma Insight and Management in Europe and Canada (EUCAN AIM) survey, 2010. http://www.takingaimatasthma.eu/docs/EUCAN_AIM_Highlights.pdf (accessed January 2014).

26 van der Meer V, Bakker MJ, van den Hout WB, Rabe KF, Sterk PJ, Kievit J et al. Internet-based self-management plus education compared with usual care in asthma: a randomized trial. Ann Intern Med 2009; 151: 110-120.

27 Reddel HK, Taylor DR, Bateman ED, Boulet LP, Boushey HA, Busse WW et al. An official American Thoracic Society/European Respiratory Society statement: asthma control and exacerbations: standardizing endpoints for clinical asthma trials and clinical practice. Am J Respir Crit Care Med 2009; 180: 59-99.

28 Price D, Ryan D, Pearce L, Bride F. The AIR study: asthma in real life. Asthma J 1999; 4: 74-78.

29 Moffat M, Cleland J, van der Molen T, Price D. Sub-optimal patient and physician communication in primary care consultations: its relation to severe and difficult asthma. Prim Care Respir J 2006; 15: 159-165.
30 Haughney J, Price D, Kaplan A, Chrystyn H, Horne R, May N et al. Achieving asthma control in practice: understanding the reasons for poor control. Respir Med 2008; 102: 1681-1693.

31 Horne R, Price D, Cleland J, Costa R, Covey D, Gruffydd-Jones K et al. Can asthma control be improved by understanding the patient's perspective? BMC Pulm Med 2007; 7: 8.

32 Giraud V, Roche N. Misuse of corticosteroid metered-dose inhaler is associated with decreased asthma stability. Eur Respir J 2002; 19: 246-251.

33 Brocklebank D, Ram F, Wright J, Barry P, Cates C, Davies L et al. Comparison of the effectiveness of inhaler devices in asthma and chronic obstructive airways disease: a systematic review of the literature. Health Technol Assess 2001; 5: $1-149$.

34 Schulte M, Osseiran K, Betz R, Wencker M, Brand P, Meyer T et al. Handling of and preferences for available dry powder inhaler systems by patients with asthma and COPD. J Aerosol Med Pulm Drug Deliv 2008; 21: 321-328.

35 Hardwell A, Barber V, Hargadon T, McKnight E, Holmes J, Levy ML. Technique training does not improve the ability of most patients to use pressurised metered dose inhalers (pMDIs). Prim Care Respir J 2011; 20: 92-96.

36 Giraud V, Allaert FA, Roche N. Inhaler technique and asthma: feasability and acceptability of training by pharmacists. Respir Med 2011; 105: 1815-1822.

37 Hanania NA, Wittman $R$, Kesten S, Chapman KR. Medical personnel's knowledge of and ability to use inhaling devices. Metered-dose inhalers, spacing chambers, and breath-actuated dry powder inhalers. Chest 1994; 105: 111-116.

38 Fletcher M, Hiles D. Continuing discrepancy between patient perception of asthma control and real-world symptoms: a quantitative online survey of 1,083 adults with asthma from the UK. Prim Care Respir J 2013; 22 431-438.

(i) $\Theta$ This work is licensed under a Creative Commons Attribution ConCommercial-NoDerivatives 4.0 International License. The images or other third party material in this article are included in the article's Creative Commons license, unless indicated otherwise in the credit line; if the material is not included under the Creative Commons license, users will need to obtain permission from the license holder to reproduce the material. To view a copy of this license, visit http:// creativecommons.org/licenses/by-nc-nd/4.0/ 